
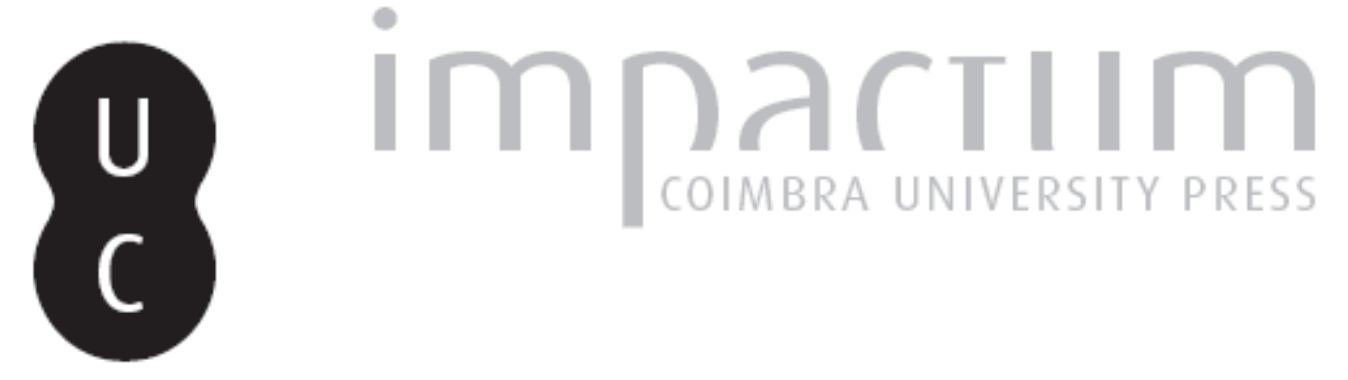

\title{
[Recensão a] V. de Saint-Point, Manifesto da mulher futurista. Manifesto futurista da luxúria, trad. de Célia Henriques
}

Autor(es): Bettini, Clelia

Publicado por: Imprensa da Universidade de Coimbra

URL persistente:

URI:http://hdl.handle.net/10316.2/42591

DOI:

DOI:https://doi.org/10.14195/0870-8584_4_20

Accessed : $\quad$ 26-Apr-2023 12:28:58

A navegação consulta e descarregamento dos títulos inseridos nas Bibliotecas Digitais UC Digitalis, UC Pombalina e UC Impactum, pressupõem a aceitação plena e sem reservas dos Termos e Condições de Uso destas Bibliotecas Digitais, disponíveis em https://digitalis.uc.pt/pt-pt/termos.

Conforme exposto nos referidos Termos e Condições de Uso, o descarregamento de títulos de acesso restrito requer uma licença válida de autorização devendo o utilizador aceder ao(s) documento(s) a partir de um endereço de IP da instituição detentora da supramencionada licença.

Ao utilizador é apenas permitido o descarregamento para uso pessoal, pelo que o emprego do(s) título(s) descarregado(s) para outro fim, designadamente comercial, carece de autorização do respetivo autor ou editor da obra.

Na medida em que todas as obras da UC Digitalis se encontram protegidas pelo Código do Direito de Autor e Direitos Conexos e demais legislação aplicável, toda a cópia, parcial ou total, deste documento, nos casos em que é legalmente admitida, deverá conter ou fazer-se acompanhar por este aviso.

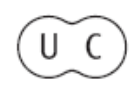




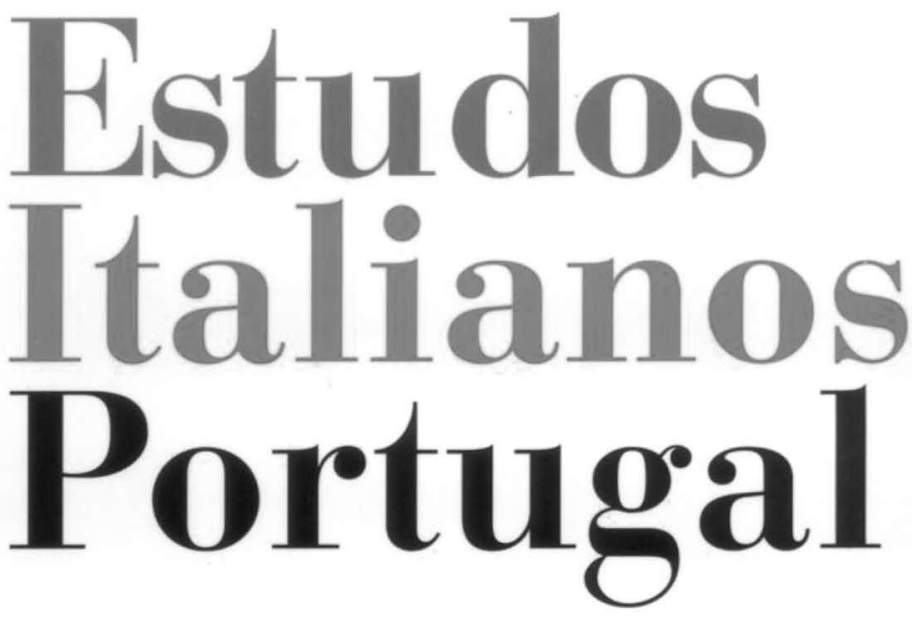

Instituto

Italiano

de Cultura

de Lisboa

Nova Série

$\mathbf{N}^{\mathbf{0}} 4$.

2009 
tas: Loti, Flaubert, Tailhade, Verlaine, Mallarmé, Schwob, Rimbaud, Gide, Merril, Kahn, Klingsor; e também, pelo lado italiano, Butti, Quaglino, Pica, Lucini, D'Annunzio. Mas são igualmente exploradas outras ligações, como é o caso de Dante, cuja memória subjaz a várias formulações que têm a ver com uma ideia-chave do Futurismo, o alcance das estrelas. Inspira La conquête des étoiles, de 1902, percorre o Manifesto de fundação e subjaz ao sucessivo Uccidiamo il chiaro di luna, do mesmo ano de 1909. Assim se compreende como o que há de decadentista e de simbolista no primeiro Marinetti se projecta através de uma vontade de superação que em si contém os gérmenes do Futurismo.

As dezoito páginas finais, onde é coligida uma bibliografia seleccionada, constituem um guia muito útil, em particular para o leitor estrangeiro, quanto a recolhas bibliográficas sobre o Futurismo; à obra de Marinetti; a antologias e compilações de manifestos; à biografia de Marinetti; a estudos críticos; e teatro. Pelo que diz respeito a este último ponto, a autora da monografia acompanha e desenvolve um tema que tem vindo a merecer, ultimamente, particular destaque, ou seja, o modo como a teatralidade recobre os mais variados aspectos da actuação futurista, de forma a converter essa vertente espectacular em instrumento fundamental daquela ambição de atrair um vasto público, tão característica dos movimentos de vanguarda. rita marnoto

\section{V. de Saint-Point, Manifesto da} mulher futurista. Manifesto futurista da luxúria, trad. de Célia Henriques, Lisboa, \& etc, 2009, pp. 75

Entre as dezenas de livros da mais variada ordem - nem todos úteis - que cada mês surgem nas estantes das livrarias portuguesas, encontrámos em Maio um que é quadrado mas, ao mesmo tempo, não o é, respeitando a marca da sua editora, a $\&$ etc de Vítor Silva Tavares, e que leva o duplo título de Manifesto da mulher futurista e Manifesto da Luxúria, por Valentine de Saint-Point. Referimos o pormenor da forma do livro não só por ser, como dissemos, um traço inimitável desta pequena-grande editora lisboeta, mas porque a história dessa esco- 
lha editorial é de directa filiação Futurista, quase a sublinhar a importância desta nova publicação dos textos de Saint-Point. Conta Vítor Silva Tavares - fundador e alma da \& etc desde os seus começos, quando isto tudo era apenas uma revista cultural do Jornal do Fundão e José Cardoso Pires ainda andava por estas bandas - que a ideia de escolher um rectângulo que contivesse em si, harmonicamente, um quadrado the veio de uma antiga conversa com Almada Negreiros. Almada tinha-lhe perguntado se sabia como tinha chegado a determinadas conclusões em relação aos Painéis atribuídos a Nuno Gonçalves e, perante a resposta negativa do amigo, Almada replicou: "Cheguei aqui sem cálculo”. Apesar de achar a afirmação de Almada apenas uma boutade futurista, o editor da futura $\mathcal{E}$ etc começou a desenhar à mão um quadrado dentro de um rectângulo, ajustando progressivamente a relativa proporção, até chegar ao formato da capa que todos conhecemos. Através da obsessão geométrica de Almada que ainda vive no invólucro deste livro, chegamos também à importância dos textos de Saint-Point que a $\mathcal{E}$ etc acaba de editar: Manifesto da $\mathrm{Mu}$ lher futurista, Manifesto da Luxúria, Amor e Luxúria, O Teatro da Mulher, As minhas estreias coreográficas e $A$ metacoreia.

O Manifesto da Luxúria já tinha sido publicado no número único da revista Portugal Futurista que viu a luz em 1917 e que recolhia os textos daqueles que, entre Lisboa e Paris, se proclamavam futuristas. Uma revista considerada perigosa e logo apreendida pela polícia, que ao conjunto de textos futuristas portugueses acrescentava dois textos em tradução: um de Filippo Tommaso Marinetti sobre o Music-hall, enérgico espectáculo futurista, e o outro de uma mulher, francesa e também futurista, o Manifesto da Luxúria de Saint-Point, declamado na I Conferência Futurista de Abril de 1917, organizada por Almada Negreiros. Teolinda Gersão, no ensaio que introduz a reedição de Portugal Futurista, atribui dois significados distintos à escolha de publicar o texto de Saint-Point: chocar um público habituado a não ouvir falar de determinados assuntos e dar uma "chicotada à nossa literatura, sobretudo lírica, [...] toda feita de amadas inexis- 
tentes de tão etéreas, de paixões sem objecto que se alimentam de si mesmas, enrodilhando-se sobre a sua própria impotência". O Manifesto da Luxúria pretendia ser, portanto, uma chapada na cara daquele público português sonolento que os Futuristas queriam despertar para a vida. E é por isso que esta nova publicação dos textos de Saint-Point nos parece um fragmento importante da memória artística portuguesa, resgatada do esquecimento por um editor clarividente, especialmente neste ano de 2009 em que se recorda o valor explosivo da vanguarda futurista.

Valentine de Saint-Point foi uma artista poliédrica com uma vida de romance. Começou poetisa, tornou-se dançarina vanguardista e acabou na miséria mais obscura, perdida entre os dédalos do Cairo. Costuma-se dizer que foi a inventora da dança como performance, uma vez que criou uma nova forma de bailado - que entendia como arte total - para a qual escolheu o nome de Metacoreia, ou seja, uma dança que "vai para além do coro", com referência ao papel do coro na tragédia grega clássica, que devia ser ultrapassado para que a dança pudesse ser também arte completa e de vanguarda, como esclarece no texto que tem como título o nome da nova dança cerebral. Para além disso, a artista não esqueceu o Teatro, outra forma de arte performativa que o Futurismo contribuiu para mudar radicalmente. Com O Teatro da Mulher, Saint-Point deixa-nos uma das mais profundas reflexões acerca da representação da mulher no teatro da época, heroína da mediocridade e de todas as fraquezas, colocando em causa poetas do calibre de D'Annunzio e Maeterlinck, como prova do facto que, "na vida, o homem não se interessa pela mulher senão através da atitute que ela desempenha na sua existência".

Porém, Saint-Point ficou célebre sobretudo por ter desafiado descaradamente a misoginia de Marinetti, que desde o Manifesto de fundação proclamava como indispensável, para a nova sociedade futurista, o "desprezo pela mulher". No Manifesto da mulher futurista, publicado simultaneamente em Paris e em Milão apenas três anos depois da difusão do Manifesto de fundação do Futurismo, a artista francesa propõe um mo- 
delo de mulher nova que não se identifica com as feministas - acusadas de quererem organizar ainda mais a sociedade em classes definidas - mas sim com os homens que desprezam a fraqueza, o sentimentalismo e a decadência femínea. Saint-Point incita as mulheres a voltar "à violência, à crueldade", para que sejam força que bombeia linfa vital na sociedade e não apenas "polvos dos lares" que tornam os homens anémicos. Esse renovado vigor da mulher contemporânea reside, para Sain-Point, precisamente na luxúria, que interpreta como força verdadeiramente futurista, como argumenta no já citado Manifesto futurista da Luxúria (1912). A luxúria "incita as Energias e desencadeia as Forças", é flor que brota das duas maiores manifestações da sensualidade, a Arte e a Guerra, desde que seja despojada de "todos os véus sentimentais que a deformam". O poder inovador da ideia de Saint-Point reside na análise muito dura do diferente significado que a luxúria adquiriu no espaço da moral cristã, que da alegria do "desabrochar de uma carne poderosa ela fez uma vergonha a esconder, um vício a renegar”. Esta mesma visão está na base de Amor e Luxúria (1913), texto publicado na revista Montjoie!, dirigida pelo companheiro di Saint-Point, um editor de origem italiana chamado Ricciotto Canudo. Trata-se de uma resposta a Camille Mauclair, intelectual de ascendência simbolista, que defendia a criação de casas de passe "para uso de mulheres solitárias ou abandonadas". Para Sain-Point isso não passaria de uma hipocrisia que levaria a esconder ainda mais o desejo, a encapsular a luxúria e, no fundo, "não a libertar-se, mas a mudar de cobardia".

Os escritos de Valentine de Saint-Point resultam vanguardistas ainda hoje, nesta nova edição quadrarectangular em língua portuguesa, bem contextualizados no seu e no nosso tempo pela introdução de Fernando Cabral Martins, pelas raras fotografias da dançarina velada e dos protagonistas da sua vida, por uma cronologia exacta daquela que foi uma verdadeira aventura intelectual e pelo prefácio de Jean Morel, que ajuda o leitor ainda novato a perceber melhor esta artista de ruptura. CLELIA BETTINI 